\title{
Ketone Measurement
}

National Cancer Institute

\section{Source}

National Cancer Institute. Ketone Measurement. NCI Thesaurus. Code C64854.

A quantitative measurement of the amount of ketones present in a sample. 